\title{
Review \\ Evaluating and monitoring analgesia and sedation in the intensive care unit
}

\author{
Curtis N Sessler ${ }^{1,2}$, Mary Jo Grap ${ }^{3}$ and Michael AE Ramsay ${ }^{4}$
}

\author{
${ }^{1}$ Division of Pulmonary and Critical Care Medicine, Department of Medicine, Virginia Commonwealth University Health System, Richmond, Virginia \\ 23298, USA \\ 2Medical Director of Critical Care, Medical College of Virginia Hospitals, Richmond, Virginia 23298, USA \\ ${ }^{3}$ Department of Adult Health Nursing, School of Nursing, VCU, East Leigh St., Richmond, Virginia 23298, USA \\ ${ }^{4}$ Department of Anesthesiology, Baylor University Medical Center, Gaston Avenue, Dallas, Texas 75246, USA
}

Corresponding author: Curtis N Sessler, csessler@vcu.edu

Published: 14 May 2008

This article is online at http://ccforum.com/content/12/S3/S2

(c) 2008 BioMed Central Ltd

Critical Care 2008, 12(Suppl 3):S2 (doi:10.1186/cc6148)

\begin{abstract}
Management of analgesia and sedation in the intensive care unit requires evaluation and monitoring of key parameters in order to detect and quantify pain and agitation, and to quantify sedation. The routine use of subjective scales for pain, agitation, and sedation promotes more effective management, including patientfocused titration of medications to specific end-points. The need for frequent measurement reflects the dynamic nature of pain, agitation, and sedation, which change constantly in critically ill patients. Further, close monitoring promotes repeated evaluation of response to therapy, thus helping to avoid over-sedation and to eliminate pain and agitation. Pain assessment tools include selfreport (often using a numeric pain scale) for communicative patients and pain scales that incorporate observed behaviors and physiologic measures for noncommunicative patients. Some of these tools have undergone validity testing but more work is needed. Sedation-agitation scales can be used to identify and quantify agitation, and to grade the depth of sedation. Some scales incorporate a step-wise assessment of response to increasingly noxious stimuli and a brief assessment of cognition to define levels of consciousness; these tools can often be quickly performed and easily recalled. Many of the sedation-agitation scales have been extensively tested for inter-rater reliability and validated against a variety of parameters. Objective measurement of indicators of consciousness and brain function, such as with processed electroencephalography signals, holds considerable promise, but has not achieved widespread implementation. Further clarification of the roles of these tools, particularly within the context of patient safety, is needed, as is further technology development to eliminate artifacts and investigation to demonstrate added value.
\end{abstract}

\section{Introduction}

Effective management of analgesia and sedation in the intensive care unit (ICU) setting requires an assessment of the needs of the patient, subjective and/or objective measurement of the key variables (such as pain, agitation, and level of consciousness), and titration of therapy to achieve specific targets [1-4]. It is important to recognize that patient needs can differ depending upon clinical circumstances, and that for any given patient therapeutic targets are likely to change over time. Thus, achieving patient comfort and ensuring patient safety, including avoidance of excessive or prolonged sedation, relies on accurately measuring pain, agitation, sedation, and other related variables utilizing validated tools that are easy to use, precise, accurate, and sufficiently robust to include a wide range of behaviors. The consequences of inadequate control of pain or agitation are considerable, but excessive or prolonged sedation is also problematic, leading to increased risk for complications of critical care. In addition to promoting a consistent, goal-directed approach to management, the systematic use of these tools enhances communication among care providers.

Here we review the available subjective instruments for evaluating pain, sedation, and agitation in the critically ill adult patient, as well as the results of validation and clinical application studies. Additionally, although objective tools, such as cerebral function monitoring, have not achieved widespread application in the ICU setting, the principles and potential roles of objective measurements related to analgesia and sedation are discussed.

\section{Assessment of pain and analgesia}

Optimal pain assessment in adult critical care settings is essential because it has been reported that $35 \%$ to $55 \%$ of

ATICE = Adaptation to Intensive Care Environment; BPS = Behavior Pain Scale; BIS = Bispectral Index; CPOT = Critical Care Pain Observation Tool; CSI = Cerebral State Index; EEG = electroencephalography; EMG = electromyogram; FLACC = Face, Legs, Activity, Cry, Consolability Observational Tool; ICU = intensive care unit; MSAT = Minnesota Sedation Assessment Tool; NPS = Numeric Pain Scale; PSI = Patient State Index; RASS = Richmond Agitation-Sedation Scale; RSS = Ramsay Sedation Scale; SAS = Sedation Agitation Scale; SCCM = Society of Critical Care Medicine; VICS = Vancouver Interactive and Calmness Scale. 
nurses underrate the patient's pain [5-7], and in one study [8] $64 \%$ of patients did not receive any medications before or during painful procedures. In the SUPPORT (Study to Understand Prognoses and Preferences for Outcomes and Risks of Treatment) study [9], nearly 50\% of patients reported pain, $15 \%$ reported moderately or extremely severe pain that occurred at least half of the time, and nearly $15 \%$ were dissatisfied with their pain control. Inaccurate pain assessment and the resulting inadequate treatment of pain in critically ill adults can have significant physiologic consequences. For example, pain increases myocardial workload, which can lead to myocardial ischemia, or to splinting, atelectasis, and a cascade of events that in turn can lead to pneumonia [10].

Patient self-report is the best indicator of pain, specifically using the numeric pain rating scale ranging from 0 to 10 . However, many critically ill patients are unable to communicate effectively because of cognitive impairment, sedation, paralysis, or mechanical ventilation. Identification of the optimal pain scale in such patients is ongoing, and no single tool is universally accepted for use in the noncommunicative patient $[1,11]$. When a patient cannot express themself, observable indicators - both physiologic and behavioral - have been treated as pain-related behaviors to evaluate pain in this population [12,13]. National pain guidelines support evaluation of both physiologic and behavioral response to pain in patients who are unable to communicate [14]. Additionally, in the Clinical Practice Guidelines for Sustained Use of Sedatives and Analgesics in the Critically III Adult published by the Society of Critical Care Medicine (SCCM) [1], regular assessment and documentation of pain and response to therapy is recommended (grade C).

There is a direct relationship between the ability to assess and document a patient's pain and the ability to manage pain $[15,16]$. However, Gelinas and coworkers [17] found that of 183 documented pain episodes in intubated patients, use of a pain scale was mentioned in only $1.6 \%$ of cases. Although assessment of patient pain behaviors was common $(73 \%$ of episodes), these assessments were observed and documented without the use of a valid and reliable pain tool. In a recent description of 1,360 mechanically ventilated, critically ill patients, Payen and coworkers [18] found that pain was not assessed in 53\% of patients who were receiving analgesia, and when pain was assessed specific pain tools were used only $28 \%$ of the time. Inadequate pain control is largely due to inconsistent use of standardized tools. Therefore, use of a valid and reliable tool to assist health care providers in the management of pain in the critically ill, sedated patient is paramount $[1,19]$.

\section{Pain assessment: communicative patients}

The Numeric Pain Scale (NPS) employs a verbal rating of pain on a scale from 0 to 10 , with 10 being the worst pain ever experienced, and is broadly used in a variety of clinical settings. It has been successfully used to evaluate pain in older adults [20], change in pain intensity [21], assessment of pain reduction [22], and evaluation of pain in geriatric patients [23], as well as in communicative critically ill patients to evaluate procedural pain [24]. Self-reported pain is considered to be the standard, and the NPS is recommended by SCCM (grade B recommendation). However, data to support its efficacy compared with other pain tools used in the noncommunicative patient are limited.

\section{Pain assessment: noncommunicative patients}

A variety of tools focusing on behavioral and physiologic indicators of pain are being used to evaluate pain intensity in noncommunicative patients, but evidence of their validity and reliability in critically ill patients is limited. Two pain scales presently used in adult critical care settings (COMFORT scale and the Face, Legs, Activity, Cry, Consolability Observational Tool [FLACC] scale) were originally developed and validated in the pediatric population. Although noncommunicative critically ill adults are similar to newborns, infants, and preverbal toddlers in being unable to report and describe pain, some behavioral components of these tools for children are not applicable to adults. Furthermore, validation of these tools in adults is limited.

\section{Pediatric pain tools adapted for use in adults}

The COMFORT scale contains behavioral and physiologic factors (eight items, each scored from 1 to 5 ) to evaluate pain and was originally designed to assess distress in pediatric ICU patients [25]. The scale measures alertness, calmness, facial tension, physical movement, muscle tone, ventilator respiratory response, blood pressure and heart rate, and it exhibits good inter-rater reliability [26].

The FLACC was developed to provide a simple and consistent method for nurses to identify, document, and evaluate pain in children $[27,28]$. The FLACC scale assesses pain by using behavioral indicators and assessment of body movements (face, legs, activity), verbal responses (cry), and consolability. It has been validated for assessing pain in children with cognitive impairment, in young children [29] and in children with postoperative pain [27], and in comparison with children's self report of pain [30]. However, there are few data to support its use in adult critically ill patients. Specific components such as cry and consolability are not appropriate for the critically ill, intubated adult.

\section{Adult-specific pain tools}

The Behavior Pain Scale (BPS) [15] is based on a sum score of three items: facial expression, movements of upper limbs, and compliance with mechanical ventilation. Based upon the assumption that a relationship exists between each score and pain intensity, each pain indicator is scored from 1 (no response) to 4 (full response), with a maximum score of 12 . Initial validity and reliability was established using 269 assessments in 30 sedated mechanically ventilated patients 
during painful procedures (endotracheal suctioning and mobilization) as well as nonpainful procedures (compression stocking application, central venous catheter dressing change). Nociceptive stimulation resulted in higher BPS values than did non-nociceptive stimuli (4.9 versus 3.5; $P<0.01$ ), whereas the groups had comparable scores prior to stimulation. Excellent inter-rater reliability was also found during multiple testing $\left(r^{2}=0.50\right.$ to 0.71$)$. Young and coworkers [30] conducted additional validity and reliability testing of the BPS in critically ill patients during routine painful and nonpainful procedures. A significant $(P<0.003)$ increase in BPS scores was found after painful procedures, and no significant increase was found after the nonpainful procedure. The odds of an increase in BPS between preprocedure and post-procedure assessments were more than 25 times higher for repositioning (painful) compared with eye care (nonpainful; $P<0.0001$ ), after controlling for analgesics and sedatives. A limitation of BPS is that responsiveness (increase in score in response to noxious stimuli) decreases substantially with deepening levels of sedation [15]. In addition, because compliance with mechanical ventilation may be considered to be a separate domain from the other behaviors, some intensivists only score facial expression and movements of upper limbs in order to assess the individual pain state.

Chanques and coworkers [31] evaluated pain in 230 ICU patients using the combination of BPS (for noncommunicative patients) and NPS (for communicative patients). The periods considered were a 21-week control phase with usual care as regards pain evaluation, and a subsequent 29-week intervention phase, during which nurses assessed pain levels using the two tools and notified physicians of high pain levels. The incidence of pain as well as the rate of severe pain events decreased significantly during the intervention phase. A significant decrease in the duration of mechanical ventilation was also noted [18].

The Adult Nonverbal Pain Scale is a modification of the FLACC scale and was developed for use in adult, noncommunicative patients. It evaluates five parameters: face, activity, guarding, physiologic I (vital signs), and physiologic II (skin and pupils). It has been pilot tested in a burn-trauma unit during all three patient care shifts in 200 paired assessments with the FLACC scale [32]. It exhibited good correlation with the FLACC scale $(r=0.86, P<0.001)$. Although it shows promise as a tool for use in the nonverbal adult population, it has not been evaluated against any other measures of pain in the adult population.

A recently developed behavior pain tool, the Critical Care Pain Observation Tool (CPOT), has four components: facial expression, body movements, muscle tension, and compliance with the ventilator for intubated patients or vocalization for extubated patients. Each of these behaviors is assigned a rating of 0 to 2 . The CPOT was adapted from three different pain assessment tools [15,25,33] and three different descriptive/qualitative studies [13,17,34]. Gelinas and coworkers [34] conducted a validation study in 105 cardiac surgery patients, using periods of rest, nociception, and 20 minutes after the nociceptive procedure (positioning) during three separate testing periods while patients were conscious and unconscious. The tool exhibited criterion validity because significant associations were found between the patients' self-reports of pain and CPOT, whereas discriminant validity was supported by higher scores during the nociceptive procedure compared with the score at rest. Inter-rater reliability was also good. Of note, changes in scores with nociceptive stimulation were similar whether the patient was conscious or unconscious.

Current practice for adult ICU patients commonly includes a combination of NPS or similar self-reported pain quantification tool, plus an instrument designed to identify pain using behavior and physiologic parameters in the noncommunicative patient. This sequential approach is supported in the form of grade B recommendations from the SCCM [1]. More work is needed to provide convincing evidence of the validity of these tools as well as to address limitations in application, such as how to assess for pain in the presence of heavy sedation. Although new scales and additional validation studies are frequently reported in this evolving field, we support use of either the BPS or CPOT for noncommunicative scales (Tables 1 and 2). Combining pain testing with a standardized approach to management can lead to better pain control without prolonging the duration of mechanical ventilation [31].

\section{Sedation and agitation scales}

The Ramsay Sedation Scale (RSS) was introduced more than 30 years ago as a subjective tool with which to evaluate precisely the level of consciousness during titration of sedative medications in the ICU [35]. Since then, numerous subjective instruments have been developed, validated, and applied in clinical and research settings to monitor level of consciousness or arousal, as well as to evaluate cognition, agitation, patient-ventilator synchrony, and other parameters. These include the Sedation Agitation Scale (SAS) [36], the Motor Activity Assessment Scale [37], the Vancouver Interactive and Calmness Scale (VICS) [38], the Richmond Agitation-Sedation Scale (RASS) [39], the Adaptation to Intensive Care Environment (ATICE) instrument [40], and the Minnesota Sedation Assessment Tool (MSAT) [41] (Table 3). In order for such a tool to be effective in the busy ICU setting, the users must be confident that it accurately measures what is intended, that it is reliable, and that it is easy to apply repeatedly by multiple care providers [42]. Desirable features of a good sedation scale have been enumerated and include the following [43]: rigorous multidisciplinary development; ease of administration, recall, and interpretation; well defined discrete criteria for each level; sufficient sedation levels for effective drug titration; assessment of agitation; and 
Table 1

\begin{tabular}{|c|c|c|}
\hline Item & Description & Score \\
\hline \multirow[t]{4}{*}{ Facial expression } & Relaxed & 1 \\
\hline & Partially tightened (for example, brow lowering) & 2 \\
\hline & Fully tightened (for example, eyelid closing) & 3 \\
\hline & Grimacing & 4 \\
\hline \multirow[t]{4}{*}{ Upper limbs } & No movement & 1 \\
\hline & Partially bent & 2 \\
\hline & Fully bent with finger flexion & 3 \\
\hline & Permanently retracted & 4 \\
\hline \multirow[t]{4}{*}{ Compliance with ventilation } & Tolerating movement & 1 \\
\hline & Coughing but tolerating ventilation for most of the time & 2 \\
\hline & Fighting ventilator & 3 \\
\hline & Unable to control ventilation & 4 \\
\hline
\end{tabular}

Scores from each of the three domains are summed, with a total score of 3 to 12 [15].

Table 2

\section{Critical Care Pain Observational Tool}

\begin{tabular}{|c|c|c|}
\hline Indicator & Description & Score \\
\hline \multirow[t]{3}{*}{ Facial expression } & No muscular tension observed & Relaxed, neutral: 0 \\
\hline & Presence of frowning, brow lowering, orbit tightening, and levator contraction & Tense: 1 \\
\hline & All of the above facial movements plus eyelid tightly closed & Grimacing: 2 \\
\hline \multirow[t]{3}{*}{ Body movements } & Does not move at all (does not necessarily mean absence of pain) & Absence of movements: 0 \\
\hline & $\begin{array}{l}\text { Slow, cautious movements, touching or rubbing the pain site, seeking attention } \\
\text { through movements }\end{array}$ & Protection: 1 \\
\hline & $\begin{array}{l}\text { Pulling tube, attempting to sit up, moving limbs/thrashing, not following } \\
\text { commands, striking at staff, trying to climb out of bed }\end{array}$ & Restlessness: 2 \\
\hline \multirow[t]{3}{*}{ Muscle tension } & No resistance to passive movements & Relaxed: 0 \\
\hline & Resistance to passive movements & Tense, rigid: 1 \\
\hline & Strong resistance to passive movements, inability to complete them & Very tense or rigid: 2 \\
\hline \multirow[t]{3}{*}{$\begin{array}{l}\text { Compliance with the } \\
\text { ventilator }\end{array}$} & Alarms not activated, easy ventilation & $\begin{array}{l}\text { Tolerating ventilator or } \\
\text { movement: } 0\end{array}$ \\
\hline & Alarms stop spontaneously & Coughing but tolerating : 1 \\
\hline & Asynchrony: blocking ventilation, alarms frequently activated & Fighting ventilator: 2 \\
\hline \multicolumn{3}{|l|}{ OR } \\
\hline \multirow[t]{3}{*}{$\begin{array}{l}\text { Vocalization } \\
\text { (extubated patients) }\end{array}$} & Talking in normal tone or no sound & $\begin{array}{l}\text { Talking in normal tone or } \\
\text { no sound: } 0\end{array}$ \\
\hline & Sighing, moaning & Sighing, moaning: 1 \\
\hline & Crying out, sobbing & Crying out, sobbing: 2 \\
\hline
\end{tabular}

Scores for each of the four domains are summed, with a total score of 0 to 8 [34].

demonstration of inter-rater reliability and evidence for validity in relevant patient populations.

\section{Recommendations and use of sedation scales in intensive care units}

The routine use of a sedation scale in ICU patients who are receiving sedative medications is endorsed in SCCM's Clinical Practice Guidelines for Sustained Use of Sedatives and Analgesics in the Critically III Adult [1] and is supported by other expert reviews [2-4]. The SCCM guidelines specifically recommend that a sedation goal or end-point should be established and regularly redefined for each patient, and that regular assessment and response to therapy should be systematically documented (grade C recommendation) [1]. The use of a validated sedation assessment scale was also specifically recommended (grade B recommendation). Additionally, the treatment algorithm depicted in the guidelines indicate that clinicians should use a sedation scale 


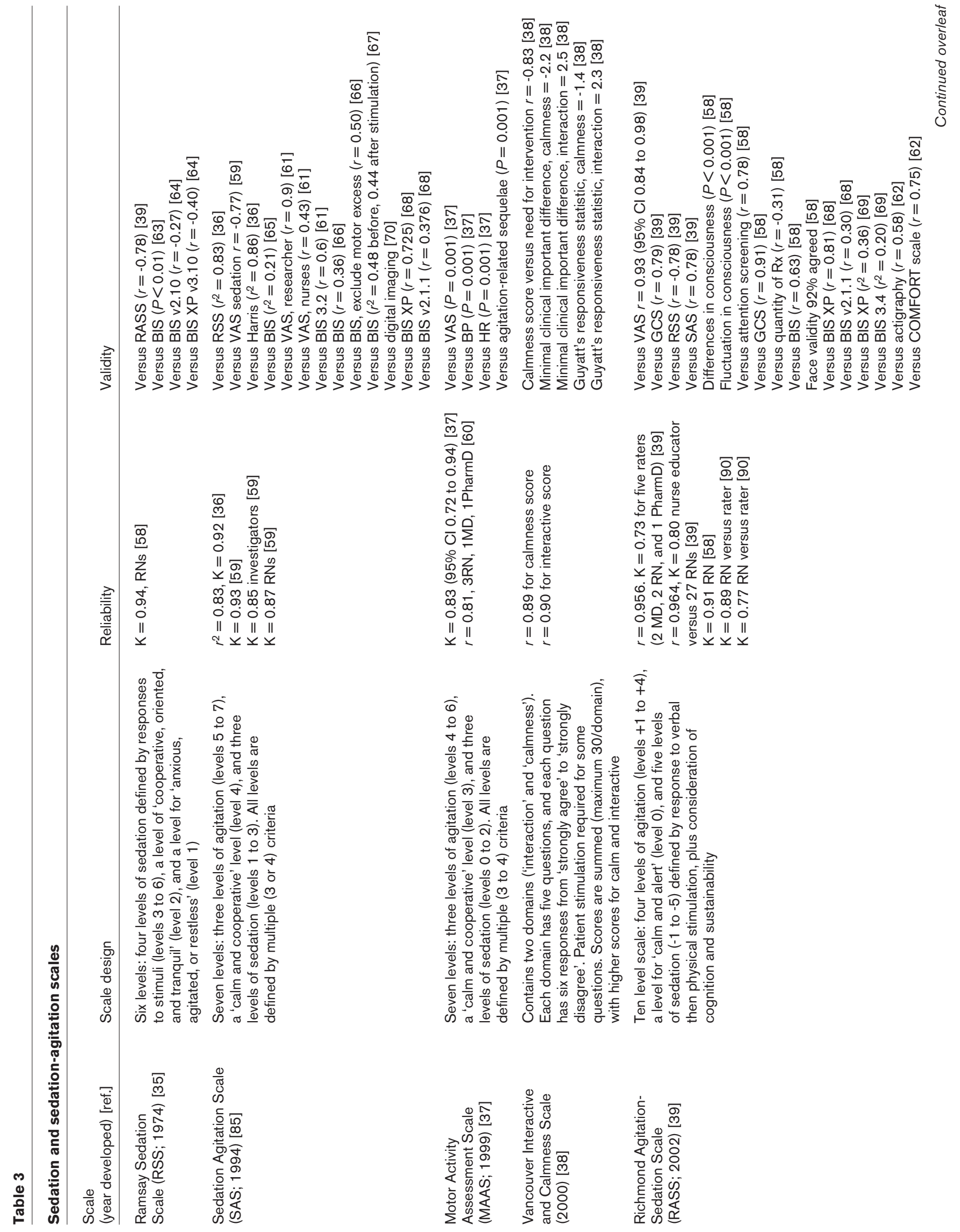




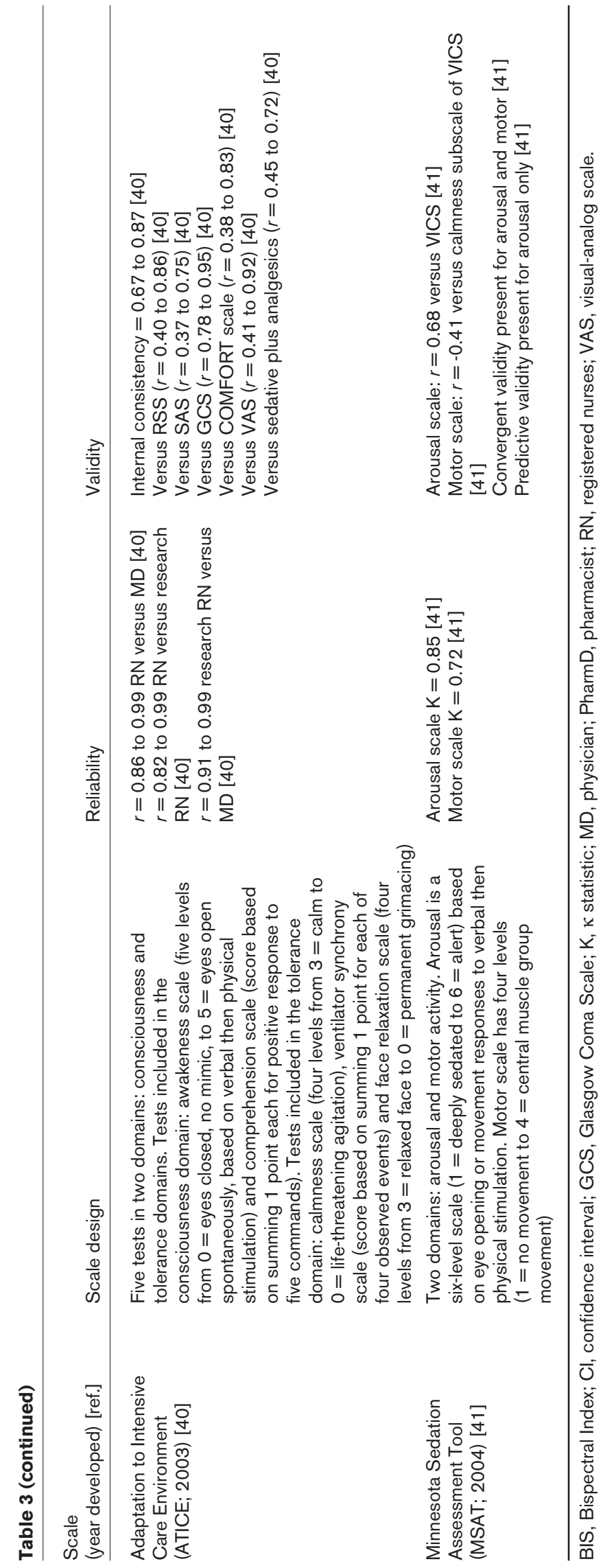

to assess for agitation/anxiety [1]. Historically, the use of a sedation scale has been disappointingly low, with sedation assessment performed in fewer than one-half of ICU patients, ICUs, and days of observation in multiple studies from throughout the world [44-50].

Although all of the aforementioned studies were performed before publication of the SCCM guidelines in 2002, a recently reported prospective surveillance study conducted in 44 ICUs during 2004 revealed that sedation assessment is still not performed in many patients who are receiving sedative drugs [18]. For example, on the second ICU day, $72 \%$ of patients were receiving sedative medications but only 43\% received sedation assessment. The missed opportunity to titrate medications effectively by using a sedation scale is apparent, because $57 \%$ of assessed patients were under deep sedation [18].

\section{Structure of sedation scales}

Each sedation scale is constructed somewhat differently (Table 3), although there are several common themes regarding domains to be evaluated and the structure of the instrument. The key domain of most scales is consciousness, typically ranging from alert to comatose, with a subdomain of arousal or awakeness, often in response to stimuli of increasing intensity (as with RSS, RASS, ATICE, and MSAT). In addition, higher states of consciousness may be further defined by testing cognition or comprehension (as with RASS and ATICE), or sustainability (as with RASS). These instruments (RSS, RASS, ATICE, and MSAT) rely upon noting a simple response (movement, eye opening, or following a command such as 'look at me') spontaneously or responses to simple cues (speaking to the patient or physically stimulating the patient) that proceed in a logical progression reflecting progressively deeper sedation [42]. This structure produces little overlap in levels of consciousness because of the step-wise approach, but the assessment can be quickly performed and the results easily recalled. In contrast, the structure of some instruments is to sum multiple subscales $[38,40]$ or to test multiple criteria for each sedation level $[36,37]$, thus adding complexity and potentially impairing ease of recall.

\section{Assessment of agitation}

Assessment of agitation, or conversely of calmness, is another important domain that is measured using many sedation instruments, either as a distinct subscale (VICS and ATICE) or incorporated into a single scale (SAS, MAAS, and RASS). With RASS various levels of agitation are assigned positive numbers, whereas sedation levels receive negative numbers, providing distinction despite the single scale design. Research suggests that the majority of ICU patients exhibit agitation at some time during their ICU stay [51]. This is an important patient safety concern because behaviors such as aggressive behavior against care givers or selfremoval of an important tube or catheter can have serious 
consequences [52-55]. Use of a sedation-agitation scale can enhance identification of agitation or anxiety, thus prompting therapeutic intervention [1] and reducing the subsequent incidence of agitation [31], as well as leading to identification and better management of pain, delirium, or other conditions that might produce agitation [2,51,54, 56,57]. It is worth emphasizing that agitated behavior may be a manifestation of inadequate pain control or it could be due to distress from a problem that requires immediate attention, such as a malpositioned endotracheal tube or myocardial ischemia.

\section{Testing of validity and reliability}

ICU sedation instruments that have been tested for inter-rater reliability and validity in multiple patient populations are summarized in Table 3, listed in order of year of publication. Inter-rater reliability has been formally tested in research investigators, as well as in clinical ICU nurses, for most of these instruments, as noted in Table 3 [36-41,58-60]. It is noteworthy that some scales such as SAS and RASS have been tested extensively, including as many as five raters representing nurses, physicians, and pharmacists, in research and clinical settings, at multiple hospitals, and in different patient populations (with or without mechanical ventilation). Excellent reliability has been demonstrated for the majority of scales. Face, construct, or criterion validity has been demonstrated for many of the domains of these instruments using a variety of comparators. These comparators include expert opinion $[40,41,59]$, quantity of sedative drug administered $[40,41,58]$, visual-analog scales $[39,59,61]$, other sedation instruments $[36,39,41,58,62]$, processed electroencephalography (EEG) such as Bispectral Index (BIS) and Patient State Index (PSI) [61,63-69], and limb acceleration and movement using actigraphy [62] or digital imaging [70] (Table 3). In most cases good to excellent validity is demonstrated. Far less work has been conducted to validate the agitation domain of sedation-agitation scales. Additionally, some scales incorporate domains that are more difficult to validate. For example, the motor activity domain of the MSAT exhibited only weak correlations with the comparator (the VICS calmness scale).

\section{Impact of the use of sedation scales}

Implementation of a sedation assessment instrument can have a positive impact on precision of sedative administration $[71,72]$, with greater frequency of appropriate sedation level and lower incidence of over-sedation, reduction in sedative and analgesic drug doses, shorter duration of mechanical ventilation, and even reduced use of vasopressor medications. Implementation of strategies that incorporate scheduled assessment for agitation, within the context of additional monitoring and targeted management, has been associated with a reduction in agitation, shorter duration of mechanical ventilation, and even fewer nosocomial infections [31,57]. Use of a sedation scale is an integral component of most patient-focused management algorithms.
The regular performance and documentation of level of sedation and agitation using a logical, easy to use, validated instrument is strongly recommended because it promotes optimal patient-focused sedation management. The authors endorse RSS and RASS (Tables 4 and 5, respectively) as sedation scales, which have excellent inter-rater reliability and validity, and were the most frequently used sedation scales in the latest survey [18].

\section{Objective measurement of cerebral function in the intensive care unit setting}

The intense management of the conscious state and mental well being are as important as critical care for any other major organ system. The brain is the most important organ in the human body, but it is not closely monitored routinely in most ICUs. Sedation scoring systems have been well validated for the management of sedation in the critical care environment, with improved outcomes when they are used effectively. Cerebral function monitors offer a more objective method of monitoring both sedation level and mental well being in the ICU. The electrical activity recorded from the cortex of the brain may be affected by cerebral perfusion, cerebral metabolism, hypoxia, sedative pharmacologic agents, and seizure activity. Cerebral insults may be detected early while they are still reversible, so that therapeutic measures may be taken. Therefore, as part of the patient safety culture now being developed in the health care system, cerebral function monitoring may be a vital tool in pursuing this objective.

\section{Cerebral function monitors}

The available cortical activity monitors record the cortical EEG signals and use the frequency, power, or disorder of these signals to determine the patient's status. These monitors process data through various proprietary algorithms to a dimensionless number that reflects the depth of sedation of the brain. The effect of sedative drugs on the electrical activity of the human brain was first reported in 1937 [73]. The very sensitive 20-channel devices were not conducive to routine clinical monitoring, so in 1969 a simpler two-channel device was developed that recorded cortical activity as a continuous power strip. The width of the power band was dependent on the amount and frequency of the cortical electrical signal [74]. Since then many different methodologies have been developed to process and simplify the EEG signal. The overall goal was to quantify the EEG signal in a display that can be easily interpreted by the practitioner. The Cooley and Tukey algorithm applied to the Fourier theorem - the Fast Fourier Transform - allows a power versus frequency histogram to be developed that may be displayed as a spectral array. This concept has led to application of these monitors as tools for the objective measurement of the depth of sedation. However, this approach relies on the concept that consciousness lies at a cortical level, which perhaps is an over-simplification of a very complex process. Cortical electrical activity may only be an expression of consciousness. 
Table 4

\begin{tabular}{ll} 
Ramsay Sedation Scale \\
\hline Score & Definition \\
\hline 1 & $\begin{array}{l}\text { Anxious and agitated or restless or both } \\
2\end{array}$ \\
3 & $\begin{array}{l}\text { Cooperative, oriented, and tranquil } \\
\text { Responds to commands only }\end{array}$ \\
5 & $\begin{array}{l}\text { Brisk response to a light glabellar tap or loud auditory } \\
\text { stimulus }\end{array}$ \\
6 & $\begin{array}{l}\text { Sluggish response to a light glabellar tap or loud } \\
\text { auditory stimulus }\end{array}$ \\
& $\begin{array}{l}\text { No response to a light glabellar tap or loud auditory } \\
\text { stimulus }\end{array}$
\end{tabular}

Performed using a series of steps: observation of behavior (score 1 or 2), followed (if necessary) by assessment of response to voice (score 3), followed (if necessary) by assessment of response to loud auditory stimulus or light glabellar tap (score 4 to 6) [35].

Table 5

Richmond Agitation-Sedation Scale

\begin{tabular}{|c|c|c|}
\hline Score & Term & Description \\
\hline+4 & Combative & $\begin{array}{l}\text { Overtly combative or violent, } \\
\text { immediate danger to staff }\end{array}$ \\
\hline+3 & Very agitated & $\begin{array}{l}\text { Pulls on or removes tube(s) or } \\
\text { catheter(s) or exhibits aggressive } \\
\text { behavior toward staff }\end{array}$ \\
\hline+2 & Agitated & $\begin{array}{l}\text { Frequent nonpurposeful movement o } \\
\text { patient-ventilator dys-synchrony }\end{array}$ \\
\hline+1 & Restless & $\begin{array}{l}\text { Anxious or apprehensive but } \\
\text { movements not aggressive or } \\
\text { vigorous }\end{array}$ \\
\hline 0 & Alert and calm & \\
\hline-1 & Drowsy & $\begin{array}{l}\text { Not fully alert, but has sustained } \\
(>10 \text { seconds) awakening, with eye } \\
\text { contact, to voice }\end{array}$ \\
\hline-2 & Light sedation & $\begin{array}{l}\text { Briefly }(<10 \text { seconds) awakens with } \\
\text { eye contact to voice }\end{array}$ \\
\hline-3 & Moderate sedation & $\begin{array}{l}\text { Any movement (but no eye contact) } \\
\text { to voice }\end{array}$ \\
\hline-4 & Deep sedation & $\begin{array}{l}\text { No response to voice, but any } \\
\text { movement to physical stimulation }\end{array}$ \\
\hline-5 & Unarousable & $\begin{array}{l}\text { No response to voice or physical } \\
\text { stimulation }\end{array}$ \\
\hline
\end{tabular}

Performed using a series of steps: observation of behaviors (score +4 to 0 ), followed (if necessary) by assessment of response to voice (score -1 to -3 ), followed (if necessary) by assessment of response to physical stimulation such as shaking shoulder and then rubbing sternum if no response to shaking shoulder (score -4 to -5) [39].

The BIS (Aspect Medical Systems, Norwood, MA, USA) is composed of time domain, frequency domain, and high-order spectral subparameters. This integrates several disparate descriptors using a proprietary algorithm into a dimensionless index. The BIS algorithm has been compared with a growing database of clinical data and continues to be updated. The resulting BIS number has been correlated with a minimal value that should be attained to prevent patient awareness under anesthesia or sedation [75]. The BIS displays a raw EEG trace obtained from a two-channel sensor but only from a unilateral prefrontal lobe site, and a power trend is displayed with a number from 0 to 100 (0 indicating no cortical activity and 100 a patient who is wide awake). There are no units of measurement and one patient's response to a sedation agent may be dependent on many factors, so whether a BIS number can correlate uniformly with depth of sedation remains controversial. The effect of the electromyogram (EMG) signal may artificially increase the BIS number. This can be detected by viewing the raw signal and seeing the high frequency of the EMG signal within the low voltage signal from EEG. Filters designed to remove the EMG signal have limited efficiency with any of the cortical monitors. However, the EMG signal may be used as a guide to the elimination of muscle relaxant drugs and the return of muscle activity - another type of twitch monitor.

The PSI, displayed on the Sedline Monitor (Hospira, Lake Forest, IL, USA), is another approach to quantifying cerebral cortical activity. This monitor has four channels and monitors both hemispheres of the brain. Similar to the BIS, the PSI converts the raw EEG signal using the Fast Fourier Theorem and a proprietary algorithm to display a dimensionless scale from 0 to 100 that reflects the depth of sedation of the patient. The scale is updated every 1.2 seconds, which makes this monitor quick to respond to changes in cerebral cortical activity. The PSI algorithm was constructed following an analysis of the quantitative EEG changes that accompanied the loss and return of consciousness after administration of sedative drugs. It was validated in a large database of patients and volunteers [76].

The Cerebral State Monitor (Danmeter A/S, Odense, Denmark) is a handheld wireless device that also uses a proprietary algorithm and a 0 to 100 scale, with 40 to 60 indicating an adequate depth of hypnosis. The Cerebral State Index (CSI) that is calculated by the device is derived from the time and frequency domain analysis, which inputs into a fuzzy logic inference system that calculates the index. In a comparative study, both the BIS and the CSI had a predictive probability statistic for depth of anesthesia of 0.87 , which demonstrates good performance [77]. The CSI performed better for deeper levels of anesthesia than the BIS, which was better at lighter levels.

The Narcotrend monitor (MonitorTechnik, Bad Bramstedt, Germany) is another monitor that processes raw EEG signals using one-channel or two-channel recordings from different electrode positions. Early models graded the depth of hypnosis into five stages from $A$ (awake) to $F$ (very deep level of anesthesia). The latest Narcotrend software (version 4.0) 


\section{PSA4000 with PSArray2}

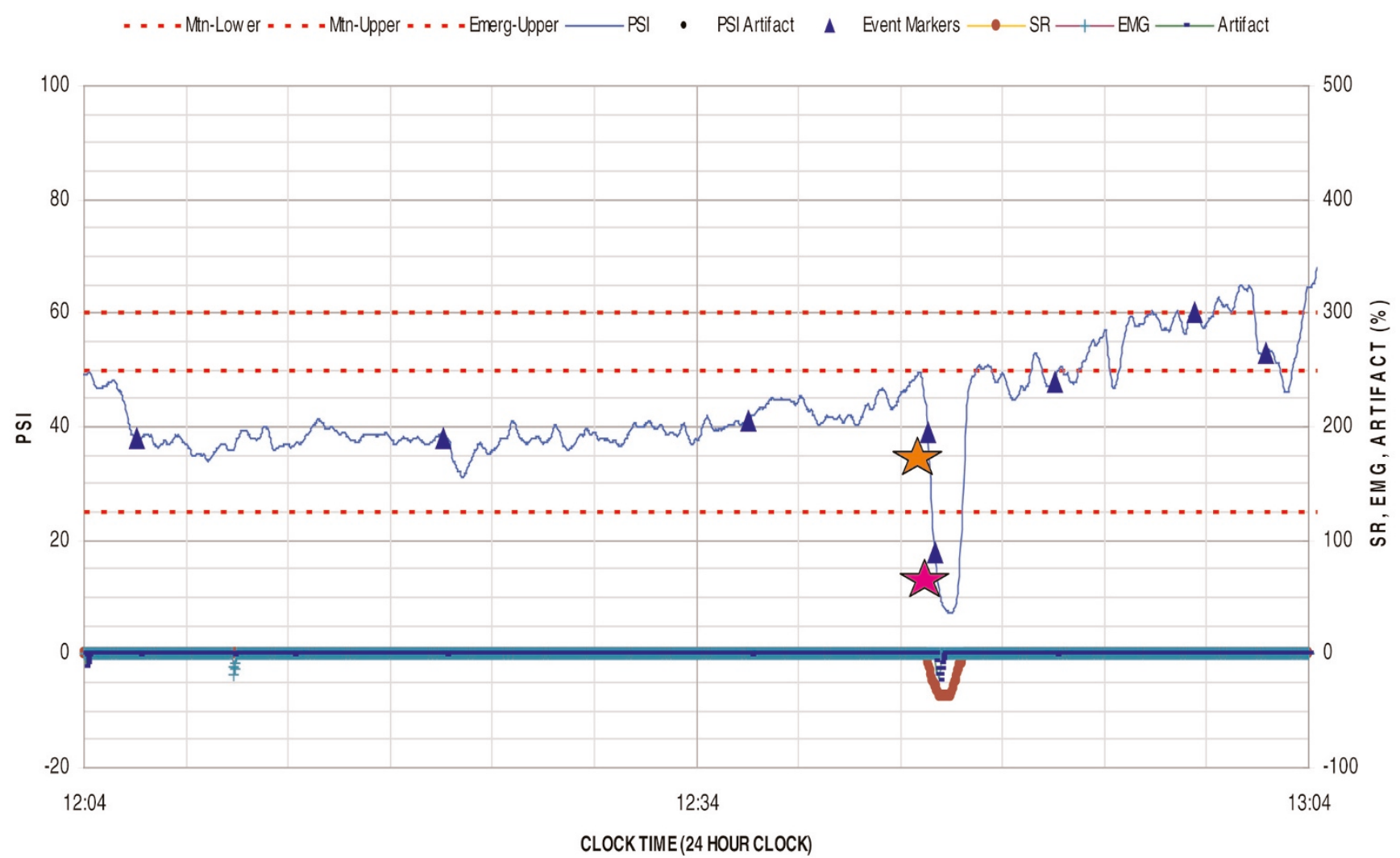

The jagged blue line represents display of Patient State Index (PSI) and suppression ratio (SR) is shown by the red line falling below 0 , over time. Solid triangles represent stimulation of patient and stars represent onset and offset of ventricular tachycardia (VT). Ventricular tachycardia with hypotension resulted in a precipitous fall in PSI and SR, with recovery following termination of VT. Reproduced with permission from Ramsay M: Role of brain function monitoring in the critical care and perioperative settings. Semin Anesth Periop Med Pain 2005, 24:195-202. [89].

now calculates the Narcotrend Index, another dimensionless 0 to 100 scale that is similar to those calculated by the monitors described above. When compared with BIS, the performance of the Narcotrend Index in terms of prediction probability of depth of sedation was slightly better than BIS (predictive probability statistic 0.88 , as compared with 0.85) [78].

\section{Additional approaches to brain monitoring}

Additional approaches to brain monitoring in the ICU include response entropy and state entropy [79]. The irregularity of the EEG signal can be quantified, and by using an algorithm that is in the public domain, quantified to reflect depth of sedation. This Entropy Monitor (GE Healthcare, Fairfield, CT, USA) utilizes the EMG signal, which may provide information useful for assessing whether a patient is responding to an external stimulus, for instance a painful stimulus. The combination of EEG and EMG is presented as the response entropy, and the lower frequency EEG signals alone are presented as the state entropy. The prediction probability values of the entropy indices for differentiating between consciousness and unconsciousness are high and comparable with those for BIS [80]. Noxious stimulation does increase the difference between response entropy and state entropy, but an increase in the difference does not always indicate inadequate analgesia [81].

Auditory evoked responses have extensively been studied with increasing depths of sedation [82]. Auditory stimuli stimulate the auditory axis, and the middle-latency auditory evoked responses are reduced in amplitude and elevated in terms of latency with increases in sedation. This Auditory Evoked Potential monitor (Danmeter A/S) studies more than just cortical electrical activity. The monitor uses an algorithm that calculates a numerical index, the Alaris Auditory Response Index $\left(A A I^{\mathrm{TM}}\right)$, from the latency and amplitude of the evoked potential. AAI ${ }^{\mathrm{TM}}$ transforms the AEP (auditory evoked potential) and the EEG signal into a value on a 0 to 100 scale that is used to measure depth of sedation. This index correlates well with the BIS index [83]. 
PSA4000 with PSArray2

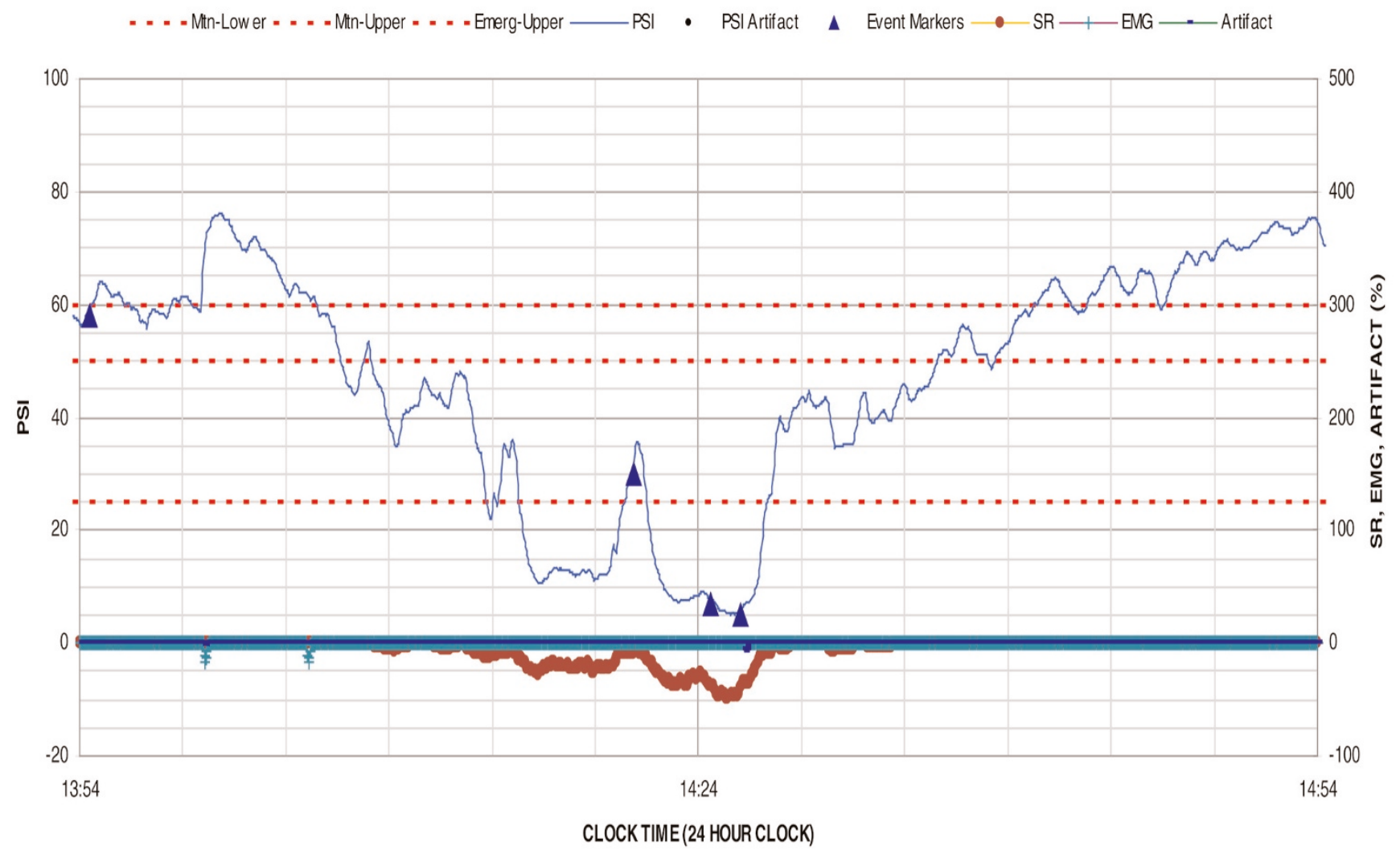

The jagged blue line represents display of Patient State Index (PSI) and suppression ratio (SR) is shown by the red line falling below 0 , over time. Solid triangles represent stimulation of patient. Accidental mis-programming of propofol infusion rate resulted in a steady decline in PSI and SR over time. Recognition of mis-programmed rate was recognized and corrected, resulting in return of PSI and SR to baseline values. Reproduced with permission from Ramsay M: Role of brain function monitoring in the critical care and perioperative settings. Semin Anesth Periop Med Pain 2005, 24:195-202. [89].

\section{The current role of objective cerebral function monitoring in the intensive care unit}

The use of these cerebral function monitors as objective monitors of depth of sedation in the ICU has not yet been universally embraced. This is because many factors may alter the signal in the critically ill patient, particularly EMG signals, which can cause erroneously high BIS and PSI scores. These artifacts can be identified by observing the raw EEG signal and seeing a very high frequency low voltage 'noise' within the EEG signal. Thus, an understanding of the basic EEG signal is important to interpreting the data presented by these cerebral function monitors. A variety of confounders, including EMG interference, sleep, drugs such as catecholamines, and temperature changes, may influence the BIS value [84]. In a comprehensive review, LeBlanc and colleagues [84] demonstrated mixed results when BIS was correlated with clinical sedation scales, with $r^{2}$ ranging from 0.21 to 0.93 . Much of the variability is probably related to EMG interference, because BIS values decline significantly when muscle relaxants are administered to ICU patients $[85,86]$.

Where does cerebral function monitoring fit into current ICU practice? The recommendations found in SCCM's Clinical Practice Guidelines, published in 2002, do not endorse routine use [1]. They state that 'objective measures of sedation such as BIS have not yet been evaluated and are not yet proven in the ICU', based upon grade $\mathrm{C}$ evidence. Although there is evidence for better operating room outcomes, such as early recognition of unintended awareness [75] or better anesthetic management [87], such evidence is scant in the ICU setting. The incidence of unintended awareness in the ICU is unknown and is mainly observed in those patients who are paralyzed either as a result of their disease process or the use of muscle relaxants. This patient group may be well served by monitoring, because the sequelae of inadequate sedation are severe. Accordingly, use of cerebral function monitoring is likely to be of greatest benefit in patients who 
are deeply sedated or who are receiving muscle relaxant medications $[1,88]$. The most compelling reason to promote further research and clinical experience in cerebral function monitoring in the ICU is patient safety. Examples of changes in PSI in response to clinical events are noted in Figures 1 and 2 [89]. Cerebral insults may be detected at a stage when they are still reversible. The brain is the most complex and most important organ in the human body and deserves more attention than it currently receives. Cerebral function monitors may provide another level of safety for our patients and, as this area of technology advances, improved care of the mental and cognitive functions of the critical care patient is likely to follow.

\section{Conclusion}

Evaluation and monitoring of pain, agitation, and level of consciousness can be accomplished by subjective scales that can contribute to enhanced communication among care givers and to more effective analgesia and sedation management. These relatively simple tools can be repeatedly applied, promoting close monitoring of changing circumstances and response to therapy. Some instruments add other measures of patient tolerance of the ICU environment, such as patientventilator synchrony. More work is needed to promote more widespread use of these tools and to address barriers to implementation. Furthermore, strategies that examine multiple aspects of patient distress and comfort, including tolerance to the ICU and interventions, are increasingly important. Future directions also include advancing the technology of objective monitoring of cerebral function in order to allow better adaptation to the ICU setting (as compared with the operating theater) and demonstrating benefits in meaningful outcomes as a result of continuous, objective monitoring.

\section{Competing interests}

CNS has received a research grant from Hospira (Physiometrix) and a consultancy fee from Hospira. MJG declares that she has no competing interests. MAER has received research grants and honoraria from Hospira.

\section{Acknowledgements}

This article is part of Critical Care Volume 12 Supplement 3: Analgesia and sedation in the ICU. The full contents of the supplement are available online at http://ccforum.com/supplements/12/S3.

Publication of the supplement has been funded by an unrestricted grant from GlaxoSmithKline.

\section{References}

1. Jacobi J, Fraser GL, Coursin DB, Riker RR, Fontaine D, Wittbrodt ET, Chalfin DB, Masica MF, Bjerke HS, Coplin WM, et al.: Clinical practice guidelines for the sustained use of sedatives and analgesics in the critically ill adult. Crit Care Med 2002, 30:119-141.

2. Sessler CN, Grap MJ, Brophy GM: Multidisciplinary management of sedation and analgesia in critical care. Semin Respir Crit Care Med 2001, 22:211-225.

3. Riker RR, Fraser GL: Monitoring sedation, agitation, analgesia, neuromuscular blockade, and delirium in adult ICU patients. Semin Respir Crit Care Med 2001, 22:189-198.

4. Kress JP, Hall JB: Sedation in the mechanically ventilated patient. Crit Care Med 2006, 34:2541-2546.
5. Hamill-Ruth RJ, Marohn ML: Evaluation of pain in the critically ill patient. Crit Care Clin 1999, 15:35-54, v-vi.

6. Puntillo KA: Pain experiences of intensive care unit patients. Heart Lung 1990, 19:526-533.

7. Puntillo K: Stitch, stitch ... creating an effective pain management program for critically ill patients. Am J Crit Care 1997, 6: 259-260.

8. Puntillo KA, Wild LR, Morris AB, Stanik-Hutt J, Thompson CL, White $\mathrm{C}$ : Practices and predictors of analgesic interventions for adults undergoing painful procedures. $A m$ J Crit Care 2002, 11:415-429; quiz 430-431.

9. Desbiens NA, Wu AW, Broste SK, Wenger NS, Connors AF Jr, Lynn J, Yasui Y, Phillips RS, Fulkerson W: Pain and satisfaction with pain control in seriously ill hospitalized adults: findings from the SUPPORT research investigations. For the SUPPORT investigators. Study to Understand Prognoses and Preferences for Outcomes and Risks of Treatment. Crit Care Med 1996, 24:1953-1961.

10. McArdle P: Intravenous analgesia. Crit Care Clin 1999, 15:89104.

11. Herr K, Coyne PJ, Key T, Manworren R, McCaffery M, Merkel S, Pelosi-Kelly J, Wild L: Pain assessment in the nonverbal patient: position statement with clinical practice recommendations. Pain Manag Nurs 2006, 7:44-52.

12. Hadjistavropoulos T, LaChapelle DL, Hadjistavropoulos HD, Green S, Asmundson GJ: Using facial expressions to assess musculoskeletal pain in older persons. Eur J Pain 2002, 6: 179-187.

13. Puntillo KA, Miaskowski C, Kehrle K, Stannard D, Gleeson S, Nye $P$ : Relationship between behavioral and physiological indicators of pain, critical care patients' self-reports of pain, and opioid administration. Crit Care Med 1997, 25:1159-1166.

14. Acute Pain Management Guideline Panel: Acute Pain Management: Operative or Medical Procedures and Trauma. Clinical Practice Guideline. AHCPR Publication No. 92-0032. Rockville, MD: Agency for Health Care Policy and Research; 1992.

15. Payen JF, Bru O, Bosson JL, Lagrasta A, Novel E, Deschaux I, Lavagne $P$, Jacquot $C$ : Assessing pain in critically ill sedated patients by using a behavioral pain scale. Crit Care Med 2001, 29:2258-2263.

16. Mularski RA: Pain management in the intensive care unit. Crit Care Clin 2004, 20:381-401, viii.

17. Gelinas C, Fortier M, Viens C, Fillion L, Puntillo K: Pain assessment and management in critically ill intubated patients: a retrospective study. Am J Crit Care 2004, 13:126-135.

18. Payen JF, Chanques G, Mantz J, Hercule C, Auriant I, Leguillou JL, Binhas M, Genty C, Rolland C, Bosson JL: Current practices in sedation and analgesia for mechanically ventilated critically ill patients: a prospective multicenter patient-based study. Anesthesiology 2007, 106:687-695.

19. Shapiro BA, Warren J, Egol AB, Greenbaum DM, Jacobi J, Nasraway SA, Schein RM, Spevetz A, Stone JR: Practice parameters for intravenous analgesia and sedation for adult patients in the intensive care unit: an executive summary. Society of Critical Care Medicine. Crit Care Med 1995, 23:1596-1600.

20. Herr KA, Spratt K, Mobily PR, Richardson G: Pain intensity assessment in older adults: use of experimental pain to compare psychometric properties and usability of selected pain scales with younger adults. Clin J Pain 2004, 20:207-219.

21. Spadoni GF, Stratford PW, Solomon PE, Wishart LR: The evaluation of change in pain intensity: a comparison of the P4 and single-item numeric pain rating scales. J Orthop Sports Phys Ther 2004, 34:187-193.

22. Cepeda MS, Africano JM, Polo R, Alcala R, Carr DB: Agreement between percentage pain reductions calculated from numeric rating scores of pain intensity and those reported by patients with acute or cancer pain. Pain 2003, 106:439-442.

23. Bergh I, Sjostrom B, Oden A, Steen B: An application of pain rating scales in geriatric patients. Aging (Milano) 2000, 12:380-387.

24. Puntillo KA, White C, Morris AB, Perdue ST, Stanik-Hutt J, Thompson CL, Wild LR: Patients' perceptions and responses to procedural pain: results from Thunder Project II. Am J Crit Care 2001, 10:238-251.

25. Ambuel B, Hamlett KW, Marx CM, Blumer JL: Assessing distress in pediatric intensive care environments: the COMFORT scale. J Pediatr Psychol 1992, 17:95-109.

26. De Jonghe B, Cook D, Appere-De-Vecchi C, Guyatt G, Meade M, 
Outin $\mathrm{H}$ : Using and understanding sedation scoring systems: a systematic review. Intensive Care Med 2000, 26:275-285.

27. Merkel SI, Voepel-Lewis T, Shayevitz JR, Malviya S: The FLACC: a behavioral scale for scoring postoperative pain in young children. Pediatr Nurs 1997, 23:293-297.

28. Manworren RC, Hynan LS: Clinical validation of FLACC: preverbal patient pain scale. Pediatr Nurs 2003, 29:140-146.

29. Merkel S: Pain assessment in infants anf young children: the Finger Span Scale. Am J Nurs 2002, 102:55-56.

30. Young J, Siffleet J, Nikoletti S, Shaw T: Use of a Behavioural Pain Scale to assess pain in ventilated, unconscious and/or sedated patients. Intensive Crit Care Nurs 2006, 22:32-39.

31. Chanques G, Jaber S, Barbotte E, Violet S, Sebbane M, Perrigault PF, Mann C, Lefrant JY, Eledjam JJ: Impact of systematic evaluation of pain and agitation in an intensive care unit. Crit Care Med 2006, 34:1691-1699.

32. Odhner M, Wegman D, Freeland N, Steinmetz A, Ingersoll GL: Assessing pain control in nonverbal critically ill adults. Dimens Crit Care Nurs 2003, 22:260-267.

33. Mateo OM, Krenzischek DA: A pilot study to assess the relationship between behavioral manifestations and self-report of pain in postanesthesia care unit patients. J Post Anesth Nurs 1992, 7:15-21.

34. Gelinas C, Fillion L, Puntillo KA, Viens C, Fortier M: Validation of the critical-care pain observation tool in adult patients. $\mathrm{Am} \mathrm{J}$ Crit Care 2006, 15:420-427.

35. Ramsay MA, Savege TM, Simpson BR, Goodwin R: Controlled sedation with alphaxalone-alphadolone. BMJ 1974, 2:656659.

36. Riker RR, Picard JT, Fraser GL: Prospective evaluation of the Sedation-Agitation Scale for adult critically ill patients. Crit Care Med 1999, 27:1325-1329.

37. Devlin JW, Boleski G, Mlynarek M, Nerenz DR, Peterson E, Jankowski M, Horst HM, Zarowitz BJ: Motor Activity Assessment Scale: a valid and reliable sedation scale for use with mechanically ventilated patients in an adult surgical intensive care unit. Crit Care Med 1999, 27:1271-1275.

38. de Lemos J, Tweeddale M, Chittock D: Measuring quality of sedation in adult mechanically ventilated critically ill patients. the Vancouver Interaction and Calmness Scale. Sedation Focus Group. J Clin Epidemio/ 2000, 53:908-919.

39. Sessler CN, Gosnell MS, Grap MJ, Brophy GM, O'Neal PV, Keane KA, Tesoro EP, Elswick RK: The Richmond AgitationSedation Scale: validity and reliability in adult intensive care unit patients. Am J Respir Crit Care Med 2002, 166:1338-1344.

40. De Jonghe B, Cook D, Griffith L, Appere-de-Vecchi C, Guyatt G, Theron V, Vagnerre A, Outin $\mathrm{H}$ : Adaptation to the Intensive Care Environment (ATICE): development and validation of a new sedation assessment instrument. Crit Care Med 2003, 31: 2344-2354.

41. Weinert C, McFarland L: The state of intubated ICU patients: development of a two-dimensional sedation rating scale for critically ill adults. Chest 2004, 126:1883-1890.

42. Sessler CN: Use of sedation assessment scales in the ICU: Paying attention to what we are doing. In: Proceedings of the 6th Conference of the Center for Medication Safety and Clinical Improvement: 17 to 18 November 2005. San Diego, CA: Center for Medication Safety and Clinical Improvement; 2005:P6-P10. http://www.cardinal.com/clinicalcenter/materials/conferences/Se dationProceedings.pdf

43. Sessler CN: Sedation scales in the ICU. Chest 2004, 126: 1727-1730

44. Magarey JM: Sedation of adult critically ill ventilated patients in intensive care units: a national survey. Aust Crit Care 1997, 10:90-93.

45. Soliman HM, Melot C, Vincent JL: Sedative and analgesic practice in the intensive care unit: the results of a European survey. Br J Anaesth 2001, 87:186-192.

46. Rhoney DH, Murry KR: National survey of the use of sedating drugs, neuromuscular blocking agents, and reversal agents in the intensive care unit. J Intensive Care Med 2003, 18:139145

47. Samuelson KA, Larsson S, Lundberg D, Fridlund B: Intensive care sedation of mechanically ventilated patients: a national Swedish survey. Intensive Crit Care Nurs 2003, 19:350-362.

48. Guldbrand P, Berggren L, Brattebo G, Malstam J, Ronholm E, Winso O: Survey of routines for sedation of patients on con- trolled ventilation in Nordic intensive care units. Acta Anaesthesiol Scand 2004, 48:944-950.

49. Botha J, Le Blanc V: The state of sedation in the nation: results of an Australian survey. Crit Care Resusc 2005, 7:92-96.

50. Mehta S, Burry L, Fischer S, Martinez-Motta JC, Hallett D, Bowman D, Wong C, Meade MO, Stewart TE, Cook DJ: Canadian survey of the use of sedatives, analgesics, and neuromuscular blocking agents in critically ill patients. Crit Care Med 2006, 34:374-380.

51. Fraser GL, Prato BS, Riker RR, Berthiaume D, Wilkins ML: Frequency, severity, and treatment of agitation in young versus elderly patients in the ICU. Pharmacotherapy 2000, 20:75-82.

52. Woods JC, Mion LC, Connor JT, Viray F, Jahan L, Huber C, McHugh R, Gonzales JP, Stoller JK, Arroliga AC: Severe agitation among ventilated medical intensive care unit patients: frequency, characteristics and outcomes. Intensive Care Med 2004, 30:1066-1072.

53. Carrion MI, Ayuso D, Marcos M, Paz Robles M, de la Cal MA, Alia I, Esteban A: Accidental removal of endotracheal and nasogastric tubes and intravascular catheters. Crit Care Med 2000, 28: 63-66.

54. Cohen IL, Gallagher TJ, Pohlman AS, Dast JF, Abraham E, Papadakos PJ: The management of the agitated ICU patient. Crit Care Med 2002, 30:S97-S125.

55. Fraser GL, Riker RR, Prato BS, Wilkins ML: The frequency and cost of patient-initiated device removal in the ICU. Pharmacotherapy 2001, 21:1-6.

56. Sessler CN, Glass C, Grap MJ: Unplanned extubation: Incidence, predisposing factors, and management. J Crit IIlness 1994, 9:609-619.

57. De Jonghe B, Bastuji-Garin S, Fangio $\mathrm{P}$, Lacherade JC, Jabot J, Appere-De-Vecchi C, Rocha N, Outin H: Sedation algorithm in critically ill patients without acute brain injury. Crit Care Med 2005, 33:120-127.

58. Ely EW, Truman B, Shintani A, Thomason JW, Wheeler AP, Gordon S, Francis J, Speroff T, Gautam S, Margolin R, et al.: Monitoring sedation status over time in ICU patients: reliability and validity of the Richmond Agitation-Sedation Scale (RASS). JAMA 2003, 289:2983-2991.

59. Brandl KM, Langley KA, Riker RR, Dork LA, Quails CR, Levy H: Confirming the reliability of the sedation-agitation scale administered by ICU nurses without experience in its use. Pharmacotherapy 2001, 21:431-436.

60. Hogg LH, Bobek MB, Mion LC, Legere BM, Banjac S, VanKerkhove K, Arroliga AC: Interrater reliability of 2 sedation scales in a medical intensive care unit: a preliminary report. $A m$ J Crit Care 2001, 10:79-83.

61. Riker RR, Fraser GL, Simmons LE, Wilkins ML: Validating the Sedation-Agitation Scale with the Bispectral Index and visual analog scale in adult ICU patients after cardiac surgery. Intensive Care Med 2001, 27:853-858.

62. Grap MJ, Borchers CT, Munro CL, Elswick RK Jr, Sessler CN: Actigraphy in the critically ill: correlation with activity, agitation, and sedation. Am J Crit Care 2005, 14:52-60.

63. Mondello E, Siliotti R, Noto G, Cuzzocrea E, Scollo G, Trimarchi G, Venuti FS: Bispectral Index in ICU: correlation with Ramsay Score on assessment of sedation level. J Clin Monit Comput 2002, 17:271-277.

64. Tonner PH, Wei C, Bein B, Weiler N, Paris A, Scholz J: Comparison of two bispectral index algorithms in monitoring sedation in postoperative intensive care patients. Crit Care Med 2005, 33:580-584.

65. Simmons LE, Riker RR, Prato BS, Fraser GL: Assessing sedation during intensive care unit mechanical ventilation with the Bispectral Index and the Sedation-Agitation Scale. Crit Care Med 1999, 27:1499-1504

66. Nasraway SS Jr, Wu EC, Kelleher RM, Yasuda CM, Donnelly AM: How reliable is the Bispectral Index in critically ill patients? A prospective, comparative, single-blinded observer study. Crit Care Med 2002, 30:1483-1487.

67. de Wit M, Epstein SK: Administration of sedatives and level of sedation: comparative evaluation via the Sedation-Agitation Scale and the Bispectral Index. Am J Crit Care 2003, 12:343348.

68. Deogaonkar A, Gupta R, Degeorgia M, Sabharwal V, Gopakumaran B, Schubert A, Provencio JJ: Bispectral Index monitoring correlates with sedation scales in brain-injured patients. Crit 
Care Med 2004, 32:2403-2406.

69. Ely EW, Truman B, Manzi DJ, Sigl JC, Shintani A, Bernard GR: Consciousness monitoring in ventilated patients: bispectral EEG monitors arousal not delirium. Intensive Care Med 2004, 30:1537-1543.

70. Chase JG, Agogue F, Starfinger C, Lam Z, Shaw GM, Rudge AD, Sirisena $\mathrm{H}$ : Quantifying agitation in sedated ICU patients using digital imaging. Comput Methods Programs Biomed 2004, 76: 131-141.

71. Costa J, Cabre L, Molina R, Carrasco G: Cost of ICU sedation: comparison of empirical and controlled sedation methods. Clin Intensive Care 1994, 5(Suppl):17-21.

72. Botha JA, Mudholkar P: The effect of a sedation scale on ventilation hours, sedative, analgesic and inotropic use in an intensive care unit. Crit Care Resusc 2004, 6:253-257.

73. Gibbs F, Gibbs E, Lennox W: Effect on the electroencephalogram of certain drugs which influence nervous activity. Arch Intern Med 1937, 60:154-166.

74. Maynard D, Prior PF, Scott DF: Device for continuous monitoring of cerebral activity in resuscitated patients. BMJ 1969, 4: 545-546.

75. Myles PS, Leslie K, McNeil J, Forbes A, Chan MT: Bispectral index monitoring to prevent awareness during anaesthesia: the B-Aware randomised controlled trial. Lancet 2004, 363: 1757-1763.

76. Drover D, Ortega HR: Patient state index. Best Pract Res Clin Anaesthesiol 2006, 20:121-128.

77. Cortinez LI, Delfino AE, Fuentes R, Munoz HR: Performance of the Cerebral State Index during increasing levels of propofol anesthesia: a comparison with the Bispectral Index. Anesth Analg 2007, 104:605-610.

78. Kreuer S, Wilhelm W, Grundmann U, Larsen R, Bruhn J: Narcotrend Index versus Bispectral Index as electroencephalogram measures of anesthetic drug effect during propofol anesthesia. Anesth Analg 2004, 98:692-697.

79. Viertio-Oja H, Maja V, Sarkela M, Talja P, Tenkanen N, TolvanenLaakso H, Paloheimo M, Vakkuri A, Yli-Hankala A, Merilainen P: Description of the entropy algorithm as applied in the DatexOhmeda S/5 Entropy Module. Acta Anaesthesiol Scand 2004, 48:154-161.

80. Bruhn J, Bouillon TW, Radulescu L, Hoeft A, Bertaccini E, Shafer SL: Correlation of approximate entropy, bispectral index, and spectral edge frequency 95 (SEF95) with clinical signs of 'anesthetic depth' during coadministration of propofol and remifentanil. Anesthesiology 2003, 98:621-627.

81. Takamatsu I, Ozaki M, Kazama T: Entropy indices vs the bispectral index for estimating nociception during sevoflurane anaesthesia. Br J Anaesth 2006, 96:620-626.

82. Struys MM, Jensen EW, Smith W, Smith NT, Rampil I, Dumortier FJ, Mestach C, Mortier EP: Performance of the ARX-derived auditory evoked potential index as an indicator of anesthetic depth; a comparison with bispectral index and hemodynamic measures during propofol administration. Anesthesiology 2002, 96:803-816.

83. Anderson RE, Barr G, Jakobsson JG: Correlation beween AAIindex and the BIS-index during propofol hypnosis: a clinical study. J Clin Monit Comput 2002, 17:325-329.

84. LeBlanc JM, Dasta JF, Kane-Gill SL: Role of the bispectral index in sedation monitoring in the ICU. Ann Pharmacother 2006, 40: 490-500.

85. Vivien $B$, Di Maria S, Ouattara A, Langeron O, Coriat $P$, Riou B: Overestimation of Bispectral Index in sedated intensive care unit patients revealed by administration of muscle relaxant. Anesthesiology 2003, 99:9-17.

86. Dasta JF, Kane SL, Gerlach AT, Cook CH: Bispectral Index in the intensive care setting. Crit Care Med 2003, 31:998; author reply 998-999.

87. Gan TJ, Glass PS, Windsor A, Payne F, Rosow C, Sebel P, Manberg P: Bispectral index monitoring allows faster emergence and improved recovery from propofol, alfentanil, and nitrous oxide anesthesia. BIS Utility Study Group. Anesthesio/ogy 1997, 87:808-815.

88. Riker RR, Fraser GL, Wilkins ML: Comparing the bispectral index and suppression ratio with burst suppression of the electroencephalogram during pentobarbital infusions in adult intensive care patients. Pharmacotherapy 2003, 23:1087-1093.

89. Ramsay M: Role of brain function monitoring in the critical care and perioperative settings. Semin Anesth Periop Med Pain 2005, 24:195-202.

90. Pun BT, Gordon SM, Peterson JF, Shintani AK, Jackson JC, Foss J, Harding SD, Bernard GR, Dittus RS, Ely EW: Large-scale implementation of sedation and delirium monitoring in the intensive care unit: a report from two medical centers. Crit Care Med 2005, 33:1199-1205.
Disclaime

This article is part of Critical Care Volume 12 Supplement 3: Analgesia and sedation in the ICU. Publication of the supplement has been funded by an unrestricted grant from GlaxoSmithKline. GlaxoSmithKline has had no editorial control in respect of the articles contained in this publication.

The opinions and views expressed in this publication are those of the authors and do not The opinions and views expressed in this publication are those of the authors and do not indications and methods of use for medicinal prod

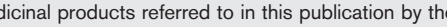
authors may reflect their research or clinical experience, or may be derived from professiona literature or other sources. Such dosages, indications and methods of use may not reflect the prescribing information for such medicinal products and are not recommended by the publisher or GlaxoSmithKline. Prescribers should consult the prescribing information approved for use in their country before the prescription of any medicinal product. Whilst every effort is made by the publisher and editorial board to see that no inaccurate or misleading data, opinion, or statement appear in this publication, they wish to make it clear that the data and opinions appearing in the articles herein are the sole responsibility of the contributor concerned.

Accordingly, the publishers, the editor and editorial board, GlaxoSmithKline, and their respective employees, officers and agents accept no liability whatsoever for the consequences of such inaccurate or misleading data, opinion or statement 